\title{
The relationship between slope gradient and lateritic cobble orientation with respect to shape, northwestern Taiwan
}

\author{
Hongey Chen · B.R. Tsai
}

\begin{abstract}
In situ investigations of lateritic cobble slopes have demonstrated that where the grain orientation is more uniform, the anisotropy is more obvious. Grain orientation will also affect the slope gradient and slope surface. The slope forms an escarpment when the intersection between the cobble orientation strike and the slope surface ranges between 90 and $180^{\circ}$. By contrast, there is a dip-slope geometry when the angle of intersection is $0^{\circ}$. The slope gradient increases and has an angle of 50 to $80^{\circ}$ when the intersected angle ranges from 0 to $180^{\circ}$. The results indicate a positive relationship between these two factors. The slope grade will increase when the disk and bladed grain shape of the cobbles increase their percentage relative to the material composition. On the other hand, the slope gradient decreases when the proportion of equant and roller grain shapes of cobble increase in the composition.
\end{abstract}

Keywords Cobble Orientation - Intersected angle of strike $\cdot$ Grain shape $\cdot$ Northwestern Taiwan

\section{Introduction}

A particular morphology and sedimentary environment is necessary to form a depositional area for rock fragments.

Received: 26 November 2001 / Accepted: 5 February 2002 Published online: 28 March 2002

(C) Springer-Verlag 2002

\section{H. Chen $(\square)$}

Department of Geosciences,

National Taiwan University,

245 Choushan Road, Taipei, Taiwan

E-mail: hchen@ccms.ntu.edu.tw

Tel.: +886-02-23636994

Fax: $+886-02-23636095$

B.R. Tsai

Bureau of Reconstruction,

Taipei City Government,

Republic of China
Rock fragments, such as boulders and cobbles, are transported downstream from higher slopes by debris flows, floods, and turbidity currents (Pettijohn 1975). The thickness of these deposits varies widely because the water volume of each flood and the up-slope material availability varies greatly over time. The deposit will have a matrix supported structure when large boulders are floated within the fine fractions. A grain supported structure will form when a great volume of boulders enters the turbid regime (Nemec and Steel 1984).

The principal sources of sand and cobble are relatively young, unconsolidated superficial deposits accumulated since the onset of the late Pleistocene. Sand, cobbles, and the fine fractions may be spread extensively over the floodplain during flooding. Cobbles are commonly found under a silt cover widely spread over the deposit by flooding. The terrace deposits are commonly cobble-rich below, becoming more silty above.

The western part of Taiwan Island has a series of sedimentary deposits from the late Miocene. Many of these formations have formed from deposited sand and mud. The cobbles and boulders mentioned above appear occasionally in these formations, forming several terraces of that era from the Penglai orogeny after the Pliocene (Ho 1986). Landslides and debris flows often occur on these terraces. Landslide areas total approximately $21.26 \mathrm{ha}$, representing $10.54 \%$ of the total slope area, in the Linkou terrace. They are composed of lateritic soil and flat-lying cobble deposits (Liao and others 1987). Landslides are a serious problem in slopes that are composed predominantly of lateritic soil and cobbles. In this paper, cobbles are considered to be irregular ovoid-shaped materials sized between 4.75 and $300 \mathrm{~mm}$. This definition is taken from the Unified Soil Classification System (Wagner 1957).

Wan and others (1986) point out that the lateritic material is a result of weathering processes on cobbles involving acid $\mathrm{pH}$ and varying degrees of wind and precipitation. The iron absorbs the clay fractions and forms a mass that will collapse and decrease dramatically in shear strength when it is immersed (Newill 1962).

Matheson (1986) and Matheson and Parent (1989) point out that when the percentage of cobbles is less than $70 \%$, the shear strength will be governed by matrix support in the lateritic cobble material. Day (1993) demonstrated that with a cobble content of more than $70 \%$, the vertical deformation would be governed by the percentage of cobbles in the lateritic cobble material. 
Laboratory tests have revealed that the major mechanism of slope failure in the Linkou terrace was triggered by heavy precipitation forming a wet zone and creating a shallow failure (Hung and others 1985; Chen 1990). Chen and Chen (1991) used some combined engineering characteristics of lateritic cobble materials in the terraces for comparison. They pointed out that the high proportion of matrix support usually governs the mechanical behavior of slope stability in lateritic cobble formations. These results imply that investigations of the mechanical properties of terraces must consider the percentage of cobbles present. This paper examines slope stability with respect to the orientation of lateritic cobbles and the distribution of slopes in northwestern Taiwan. The aim of this study is to gain an understanding of the relationships between the cobble orientation, cobble shapes, slope gradients, and slope stability. The study was based on the Linkou, Taoyuan, and Tadu terraces in northwestern Taiwan (Fig. 1). All of them are of late Pleistocene age (Ho 1986).

\section{Criteria for outcrop selection}

Outcrops were selected according to the following criteria: (1) the slope has not undergone diagenesis and is not part of a rock basement, (2) the slope has no vegetation cover, and (3) the slope has slid into its current fresh slope condition. In this study, 105 sites were selected for analysis. The Linkou terrace had 32 sites, the Taoyuan area had 35 sites, and the Tadu area had 38 sites.

\section{Geological setting}

The island of Taiwan is located on the boundary of the tectonic collision zone arising from the Philippine Sea plate toward the southeast and the Eurasian Continental plate toward the northwest. The island is $75 \%$ mountainous and 25\% low-lying hills, alluvial plains, and terraces. The terraces are mostly located in the western half of the island. The mountains are quite steep due to their relatively young age. In general, the eastern part of this island is composed of metamorphic rocks of the Mesozoic to the late Paleozoic age (Ho 1986). The western part is sedimentary rock of Miocene age and the northern part is volcanic rock of Pleistocene age.

Terraces are a major terrain feature in northwestern Taiwan, and are common throughout the island except in the Hengchun area in the south. These terraces from north to south include the Linkou terrace, the Taoyuan terrace, and the Tadu terrace (Yang 1986; Lin 1991). Interlayered gravel, sand, and mud of the late Pleistocene underlie these terraces. There is often a cover of a thin veneer lateritic soil. This sedimentary sequence has been explained in terms of alluvial fan, delta, coastal, and transitional coastal environments (Chen and Teng 1990).

\section{Linkou terrace}

The elevation of the Linkou terrace is around 200 to $250 \mathrm{~m}$ and creates a triangular area. The predominant lithology of the Linkou terrace comprises loose and uncemented Linkou and Tanawan formations. The thickness of the Linkou Formation is over $300 \mathrm{~m}$ and it is mainly composed of conglomerate. This formation is distributed on the eastern part of the Linkou terrace. The Tanawan Formation mainly consists of mud, sand, and conglomerate. This formation is distributed on the western and southern parts of the Linkou terrace (Chen and Teng 1990).

\section{Taoyuan terrace}

The elevation of the Taoyuan terrace is approximately $244 \mathrm{~m}$. The stratigraphy of this area includes the Yangmei Formation, the Danmaupu Conglomerate, the Dienzehu Formation, the Chungli Formation, and the Taoyuan

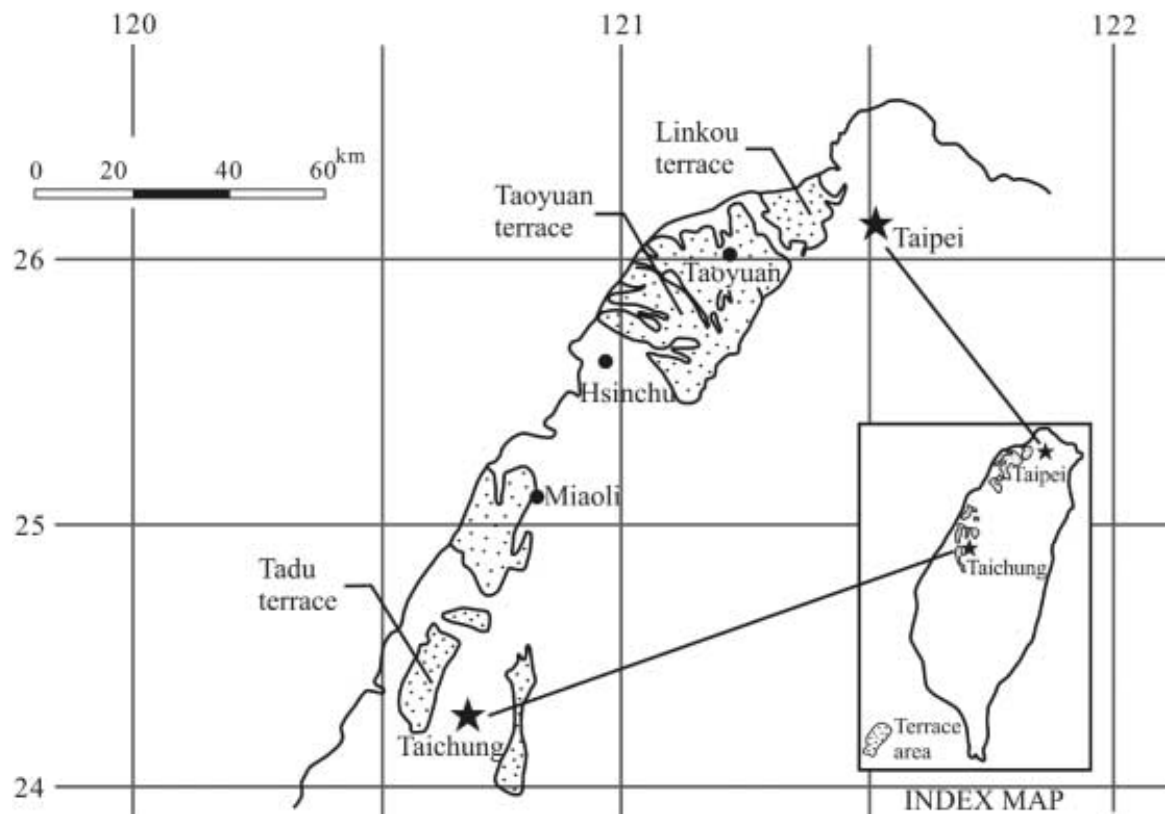

Fig. 1

Location of the study areas (Linkou, Taoyuan, and Tadu terraces) in northwestern Taiwan 


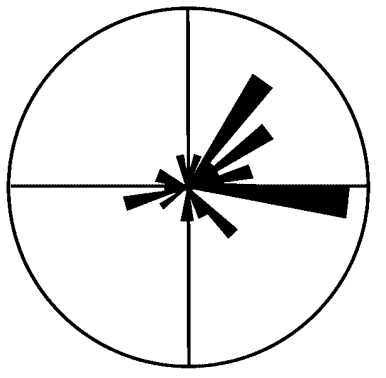

Medium (M grade)

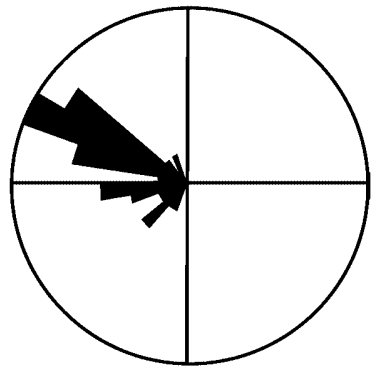

High

(H grade)

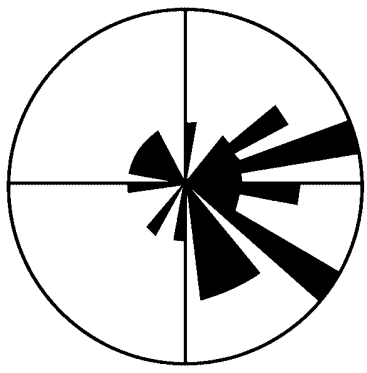

Low

(L grade)

Fig. 2

Rose diagrams of cobble orientation showing three categories of high, medium, and low grades

Formation (Tang 1964). The Yangmei Formation is the rock basement in the Taoyuan terrace. The Danmaupu Conglomerate consists of lenticular sandstone, which covers the Yangmei Formation. An unconformity was formed on the contact surface of the upper part of the terrace deposit. The Dienzehu Formation consists of lateritic cobbles. The cobble and boulder diameters range from 10 to $30 \mathrm{~cm}$.

\section{Tadu terrace}

The Tadu terrace is distributed northeast to southwest, around $21 \mathrm{~km}$ in length at an elevation of around $310 \mathrm{~m}$. The main composition of the Tadu terrace is the Toukoshan Formation, which consists of interbedded sand and

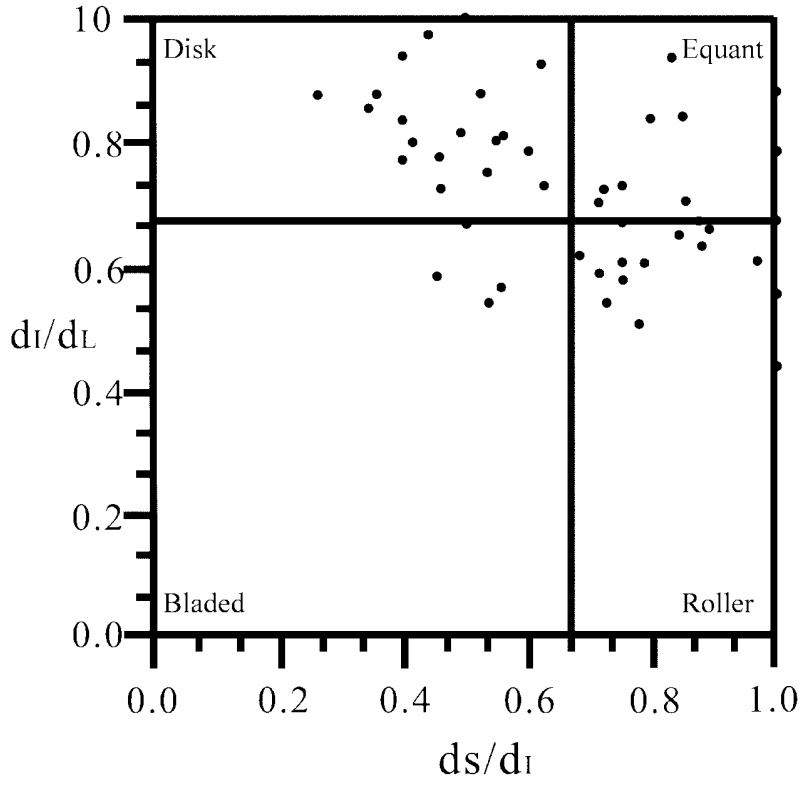

Fig. 3

Diagram of Zingg's (1935) shapes indicating the percentage of various cobble shapes in the study area

conglomerate, lateritic soil, and alluvium (Chiang 1984). The conglomerate formation is mainly composed of weakly cemented quartzite cobbles with diameters that range from 2 to $15 \mathrm{~cm}$. The thickness of the conglomerate is more than $100 \mathrm{~m}$ on its northern part but is thinner (approximately $20 \mathrm{~m}$ ) to the south. The cover of lateritic soil is around $5 \mathrm{~m}$ thick.

\section{Field measurements}

The field measurements have included: (1) slope attitude and matrix penetration; (2) grain shape and orientation; (3) grain size; and (4) photo counting.

\section{Slope attitude and matrix penetration}

A Schmidt lower hemisphere projection was used to analyze the data for slope attitude and cobble orientation. These measures of slope attitude were plotted on the
Table 1

The slope gradient distribution in Linkou terrace
Table 2

The slope gradient distribution in Taoyuan terrace

\begin{tabular}{|c|c|c|c|c|c|}
\hline Areas & Cankou & Hungshuishen River & Lenshuken & Kinkou & Denfon \\
\hline Slope gradient $\left({ }^{\circ}\right)$ & $54-77$ & $60-80$ & $68-76$ & $48-73$ & $54-80$ \\
\hline $\begin{array}{l}\text { Average }\left({ }^{\circ}\right) \\
\text { Total average: } 66^{\circ}\end{array}$ & 65 & 71 & 72 & 64 & 67 \\
\hline
\end{tabular}

\begin{tabular}{|c|c|c|c|c|c|}
\hline Areas & Pushin & Yangmei & Berkonken & Kunshi & Hukou \\
\hline $\begin{array}{l}\text { Slope gradient }\left({ }^{\circ}\right) \\
\text { Average }\left({ }^{\circ}\right)\end{array}$ & $\begin{array}{l}54-70 \\
63\end{array}$ & $\begin{array}{l}58-74 \\
64\end{array}$ & $\begin{array}{l}46-62 \\
55\end{array}$ & $\begin{array}{l}44-70 \\
63\end{array}$ & $\begin{array}{l}64-70 \\
66\end{array}$ \\
\hline Total average: $61^{\circ}$ & & & & & \\
\hline
\end{tabular}


Table 3

The slope gradient distribution in Tadu terrace

\begin{tabular}{|c|c|c|c|c|}
\hline Areas & Chinchilla & Shalu & Lonchin & Tadu \\
\hline Slope gradient $\left(^{\circ}\right)$ & $56-76$ & $60-73$ & $56-74$ & $62-82$ \\
\hline Average $\left({ }^{\circ}\right)$ & 67 & 68 & 65 & 73 \\
\hline
\end{tabular}

Table 4

The average values of physical properties in the three terrace areas. UCS Unconfined compressive strength

\begin{tabular}{|c|c|c|c|}
\hline & $\begin{array}{l}\text { Linkou } \\
\text { terrace }\end{array}$ & $\begin{array}{l}\text { Taoyuan } \\
\text { terrace }\end{array}$ & $\begin{array}{l}\text { Tadu } \\
\text { terrace }\end{array}$ \\
\hline Water content (\%) & 9.9 & 12.6 & 4.7 \\
\hline Specific gravity & 2.68 & 2.69 & 2.67 \\
\hline $\mathrm{pH}$ & 5.52 & 5.22 & 5.34 \\
\hline$>2 \mathrm{~mm}(\%)$ & 69.61 & 72.24 & 72.99 \\
\hline $2-0.074 \mathrm{~mm}(\%)$ & 16.69 & 12.01 & 15.35 \\
\hline$<0.074 \mathrm{~mm}(\%)$ & 13.69 & 15.74 & 11.64 \\
\hline Liquid limit (\%) & 28.6 & 37.3 & 28.1 \\
\hline Plastic limit (\%) & 22.4 & 25.7 & 20.9 \\
\hline Plasticity index & 6.2 & 11.6 & 7.2 \\
\hline UCS $(\mathrm{kPa})$ & 326.3 & 336.1 & 401.8 \\
\hline
\end{tabular}

stereonet using the method of great circle boundaries.

Matrix penetration measurements were obtained by using a pocket Schmitz machine.

A rose diagram illustrates the slope attitude projection and cobble orientation (Fig. 2). If the cobble orientation is uniform, the rose diagram will form an equally distributed fan shape. If the cobble orientation is random in its distribution, the rose diagram will be divergent and
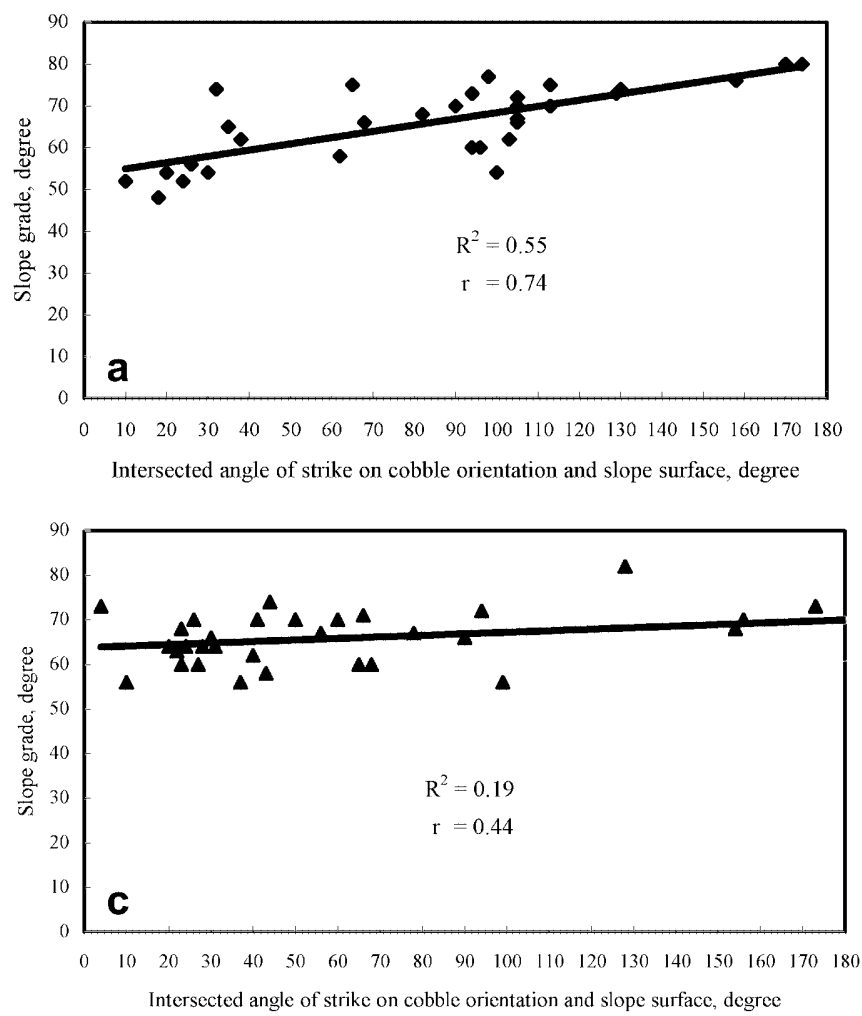
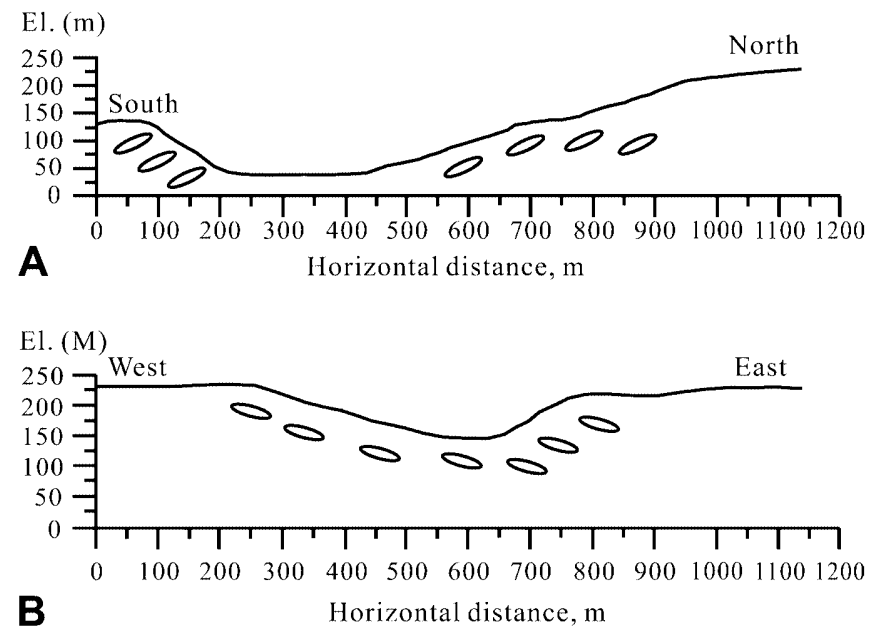

Fig. 4

Cross sections of the Cankou and the Hungshuishen river areas. The ellipsoid cobble shapes fully underlie the slope and their locations appear to influence slope shapes

include a large area in its fan shape. The diagram categories of cobble orientation could distinctly have high $(\mathrm{H})$, medium $(\mathrm{M})$, or low (L) grades (Pettijohn 1975). In these study areas, the high grade is less than $45^{\circ}$ (of a circle) in its major fan shape in the northwest

Fig. 5

Diagram showing the linear trend of the intersected angle of strike on the cobble orientation and slope surface with the slope grade in various terraces
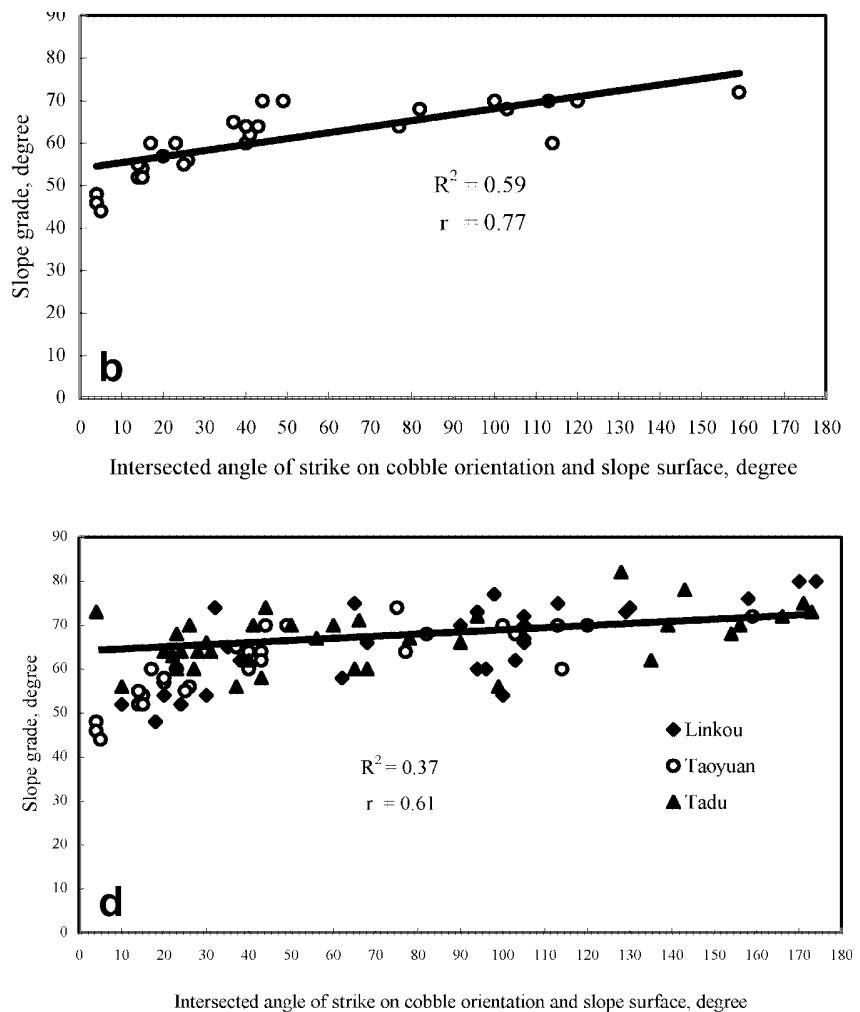

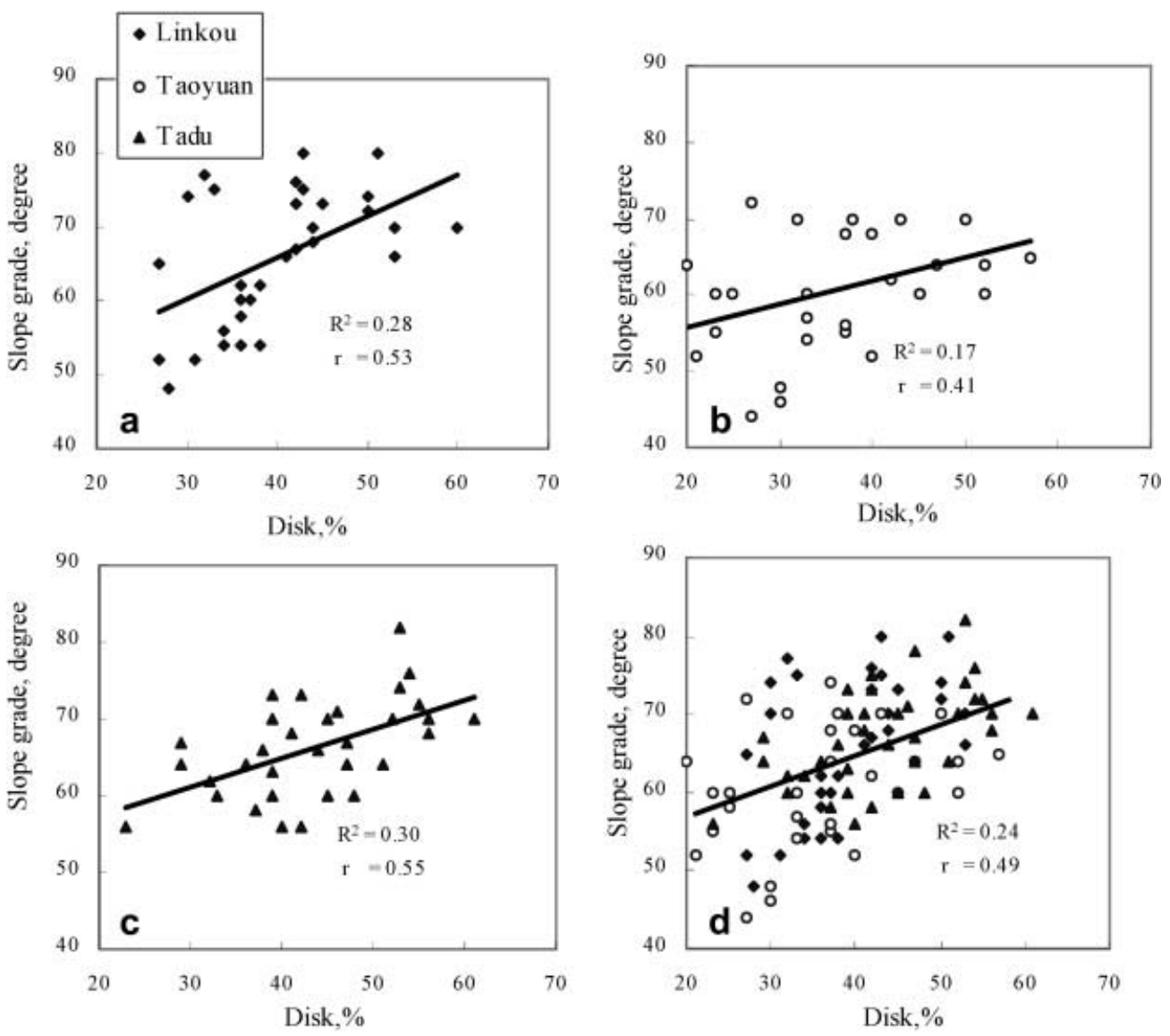

Fig. 6

Diagram displaying the relationship between the slope and the percentage of disk shapes in the three terraces quadrant of the study area. The medium grade is less than $65^{\circ}$ in its major fan shape, mostly in the northeast quadrant (overlapping slightly into the southeast quadrant) of the study area. The low grade is more than $65^{\circ}$ from approximately $\mathrm{N} 45^{\circ} \mathrm{E}$ to $\mathrm{S} 10^{\circ} \mathrm{E}$ with a very random distribution of the various orientations. In this study, the slope attitudes at the 105 outcrop sites on three terraces were measured. Thirty pocket penetrations were executed on the cobble matrices at each studied outcrop site. Matrix penetration measurements were obtained by using a pocket Schmitz machine. The matrices were bonded tightly such that they were impossible to dislodge without destroying them in the process. These penetration tests were then executed in the field and correlations were run across all the samples measured.

\section{Grain shape and orientation}

The three axes were measured for cobbles within the terraces. These were designated as $\mathrm{dL}$ for the longest axis, $\mathrm{dI}$ for the middle axis and $\mathrm{dS}$ for the shortest axis. These shape measures were undertaken in situ at points randomly chosen from the fresh outcrops of the slopes concerned. The measurements also included the strike and dip of the maximum plane (intersection of $\mathrm{dL}$ and $\mathrm{dI}$ ) in bladed cobbles at fresh slope surfaces. These measurements revealed a strike trend in which the strike consistently intersects a maximum plane of the cobbles on the slope surfaces. Zingg's shape method (1935) was then used to classify the cobble shapes in this study. Four different cobble shapes were found: disk, bladed, roller, and equant. Measures on the long (dL), middle (dI), and short (dS) cobble axes were further analyzed by considering the ratios of $\mathrm{dI} / \mathrm{dL}$ and $\mathrm{dS} / \mathrm{dI}$. The number and percentage of each of the four cobble shapes could then be deduced. For this study area, the proportion of disk-shaped cobbles was $38 \%$, equant was $24 \%$, bladed was $10 \%$, and roller was $28 \%$ (Fig. 3). These results can be used to explain the distributions of cobble shapes.

\section{Grain size}

Two separated parts of grain sizes were analyzed for their percentages in the composition. These served as the scaled-down representatives of gravel sizes above $15 \mathrm{~mm}$. One part was on gravel sizes over $15.5 \mathrm{~mm}$. The other part was on gravel sizes under $15.5 \mathrm{~mm}$. The cobble percentage can be calculated by computer analysis from two scaleddown methods of in situ visual counting and photo counting in the laboratory. These two methods provided a comparison of their respective sizes.

\section{Photo counting}

In situ photographs were taken of each unique sample. Each image was divided into a grid to enable counting of cobbles. A 17.5-mm-diameter coin was placed on top of the photos for comparing the grain sizes in the photos. The grain sizes greater than $15.5 \mathrm{~mm}$ were particularly useful in calculating their percentage. Then the grain sizes smaller than $15.5 \mathrm{~mm}$ could be distinguished and counted 

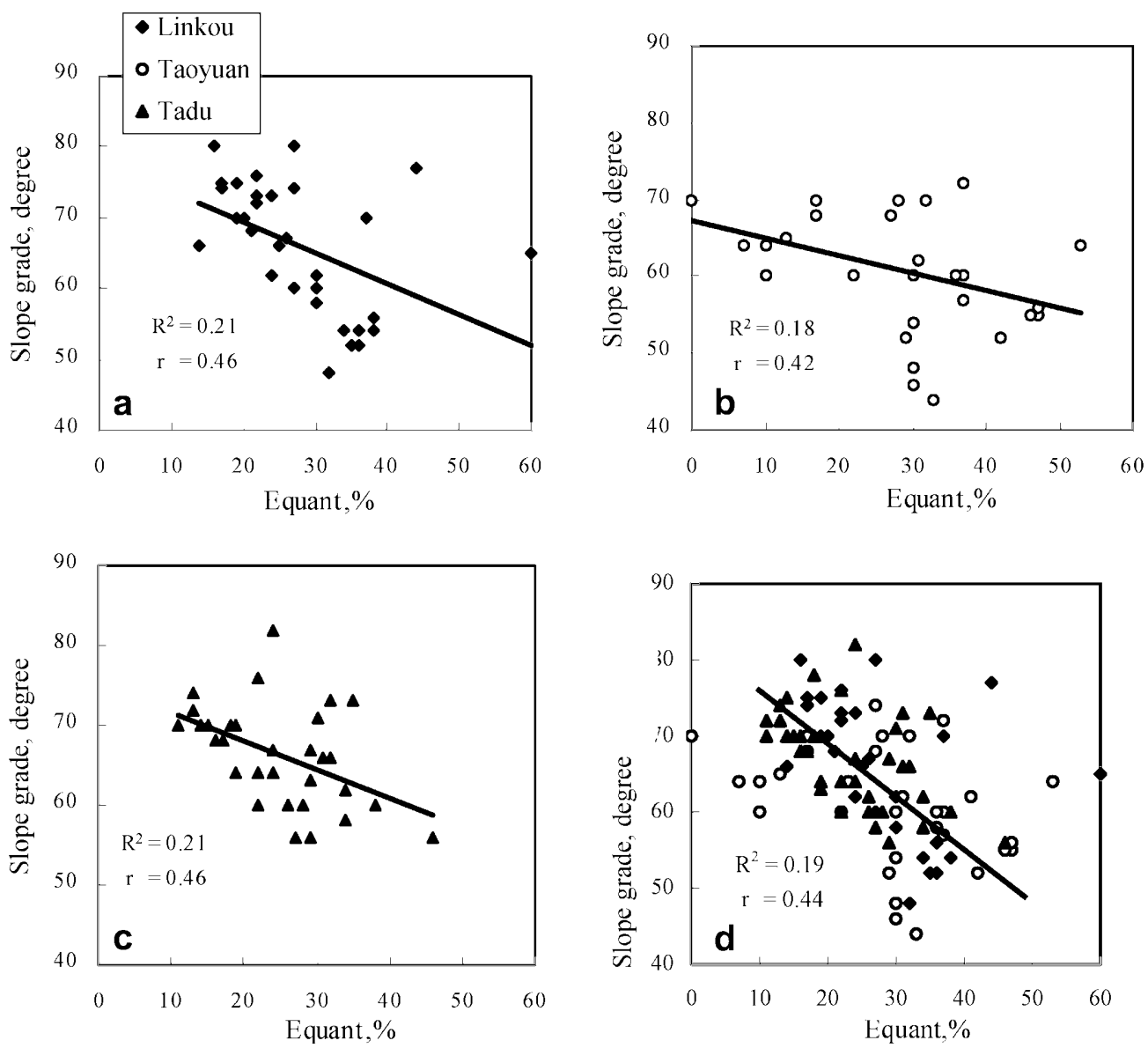

Fig. 7

Diagram displaying the relationship between the slope and the percentage of equant shapes in the three terraces

by the computer software when scanned in by a standard scanner with a given scale size included with the photo. These measures were combined for calculation of a final figure representing their particle size distribution as an averaged sum.

\section{Results}

\section{Slope gradient}

Measurements of slope gradient are summarized in Tables 1, 2, and 3. These results show that the slope gradient average is around $66^{\circ}$ in the Linkou terrace. In the Taoyuan terrace, the slope gradient average is around $61^{\circ}$. In the Tadu terrace, the average slope gradient is around $68^{\circ}$.

\section{Particle size distribution}

Particles with a size in excess $2 \mathrm{~mm}$ make up around $69.6 \%$ of the Linkou terrace. Most of the particles are cobble-sized. The percentage of particles over $2 \mathrm{~mm}$ is around $72.24 \%$ of the Taoyuan terrace and around $72.99 \%$ in the Tadu terrace. Table 4 combines the average results and shows that there is relatively little difference in the above three terraces in terms of particle sizes.

\section{Physical properties}

The geotechnical properties of the three study areas are also summarized in Table 4, and show little difference between the three terraces. These results reveal that the major characteristic of the matrices in the Linkou terrace and Tadu terrace is their low plasticity. The Taoyuan terrace has moderate plasticity.

The physical properties of the cobbles on the above terraces do not vary too much from one area to another. Changes in the slope gradient appear to be governed by (1) cobble orientation, (2) cobble shape, and (3) matrix strength.

\section{Morphological characteristics}

Two river valleys were selected for a more detailed consideration of the morphology of the Linkou terrace. One site was on the Cankou River, which is orientated in a northwestern to southeastern direction. The second was along the Hungshuishen River, which runs in a south to north direction.

Figure 4 illustrates the cobble orientation relative to the slope gradient for the Cankou River section. The cobble orientation in this area is in a east-west direction, with a dip toward the south (Fig. 4a). The southern part of the section reveals a steep slope at the intersection of the slope surface and the cobble orientation, forming an escarpment. The northern part of the Cankou River section has a gentle slope because the intersection of the slope surface and cobble orientation is a dip-slope type. 

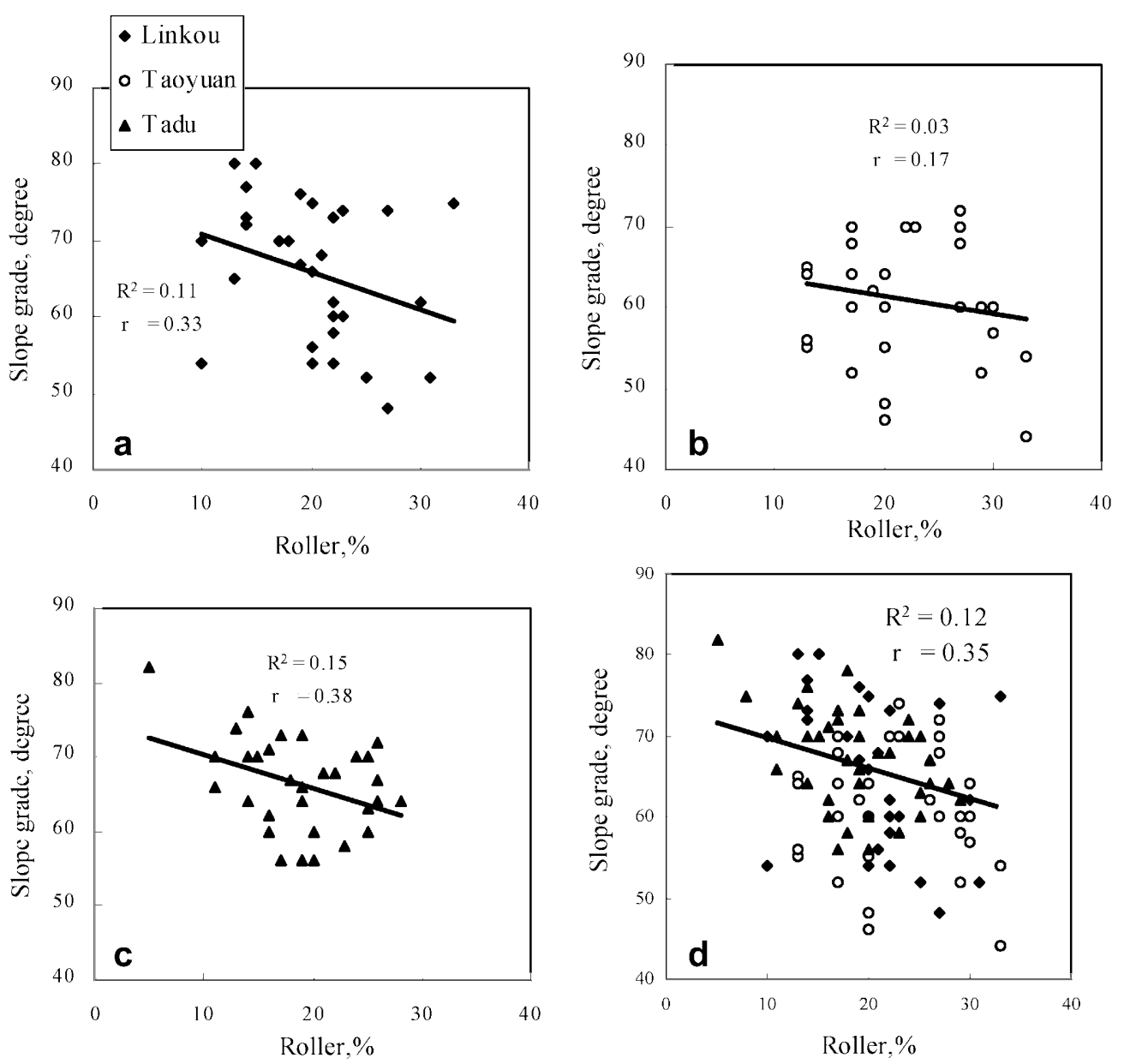

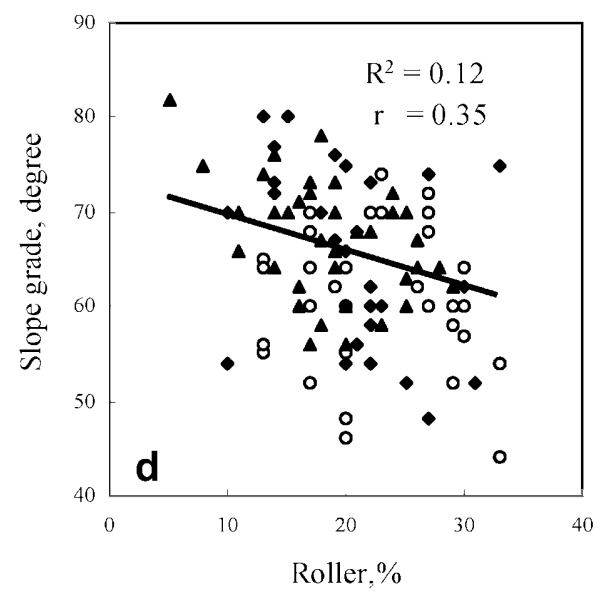

Fig. 8

Diagram displaying the relationship between the slope and the percentage of roller shapes in the three terraces
Table 5

The results of the intersected angle of strike on the cobble orientation and the slope surface, the slope gradient, and the percentage of cobble shapes in the constant strength $(\mathrm{Qu})$ $416.5 \mathrm{kPa}$ of matrix material. IA Intersected angle of strike on the cobble orientation and the slope surface

\begin{tabular}{|c|c|c|c|c|c|c|}
\hline Location & IA $\left(^{\circ}\right)$ & $\begin{array}{l}\text { Slope } \\
\text { gradient }\left(^{\circ}\right)\end{array}$ & Disk (\%) & Equant (\%) & Bladed (\%) & Roller (\%) \\
\hline LK9 & 174 & 80 & 43.33 & 26.67 & 16.67 & 13.33 \\
\hline LK11 & 35 & 65 & 26.67 & 60.00 & 0.00 & 13.33 \\
\hline LK14 & 130 & 74 & 50.00 & 16.67 & 10.00 & 23.33 \\
\hline LK14-2 & 94 & 73 & 42.43 & 24.37 & 11.25 & 21.95 \\
\hline LK21 & 105 & 72 & 50.39 & 21.65 & 14.36 & 13.60 \\
\hline LK21-1 & 129 & 73 & 45.37 & 22.37 & 17.89 & 14.38 \\
\hline BK1-3 & 14 & 52 & 21.05 & 42.11 & 7.89 & 28.95 \\
\hline HK5 & 43 & 64 & 46.67 & 6.67 & 26.67 & 20.00 \\
\hline KC9 & 5 & 44 & 26.67 & 33.33 & 6.67 & 33.33 \\
\hline PH1-1 & 44 & 70 & 43.33 & 16.67 & 13.33 & 26.67 \\
\hline TD1-4 & 173 & 73 & 41.67 & 31.25 & 8.33 & 18.75 \\
\hline TD6 & 154 & 68 & 56.25 & 16.67 & 6.25 & 20.83 \\
\hline TD13-1 & 78 & 67 & 47.06 & 29.41 & 5.88 & 17.65 \\
\hline TD16-1 & 60 & 70 & 38.89 & 13.89 & 22.22 & 25.00 \\
\hline TD17-1 & 37 & 58 & 42.42 & 27.27 & 12.12 & 18.18 \\
\hline TD17 & 94 & 72 & 55.26 & 13.16 & 7.89 & 23.68 \\
\hline
\end{tabular}

The cobble orientation of the Hungshuishen River has a northeastern direction and the dip is toward the south (Fig. 4b). The eastern part of the section in the Hungshuishen River reveals an escarpment-slope type at the intersection of the slope surface and cobble orientation (Fig. 4b). The western part of the Hungshuishen River has a gentle slope because the intersection of its slope surface and the cobble orientation is a dip-slope type.
The results of this site investigation demonstrate that changes in the cobble orientation range from irregular to uniform in response to local changes in topography.

\section{Orientation effects}

The angle of intersection of the strike of the cobble orientation and the slope surface can be used to analyze the relationship between the cobble orientation and slope 

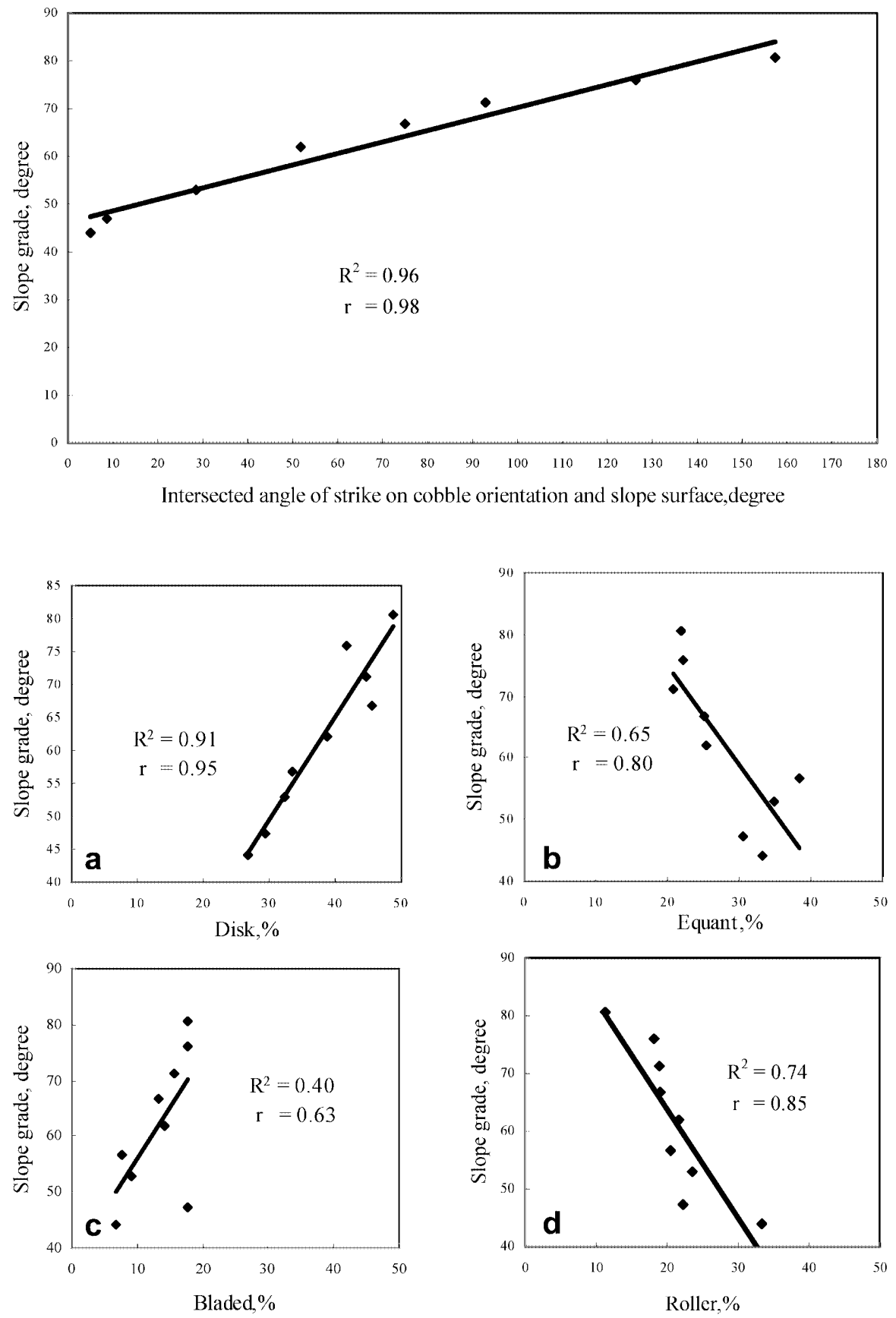
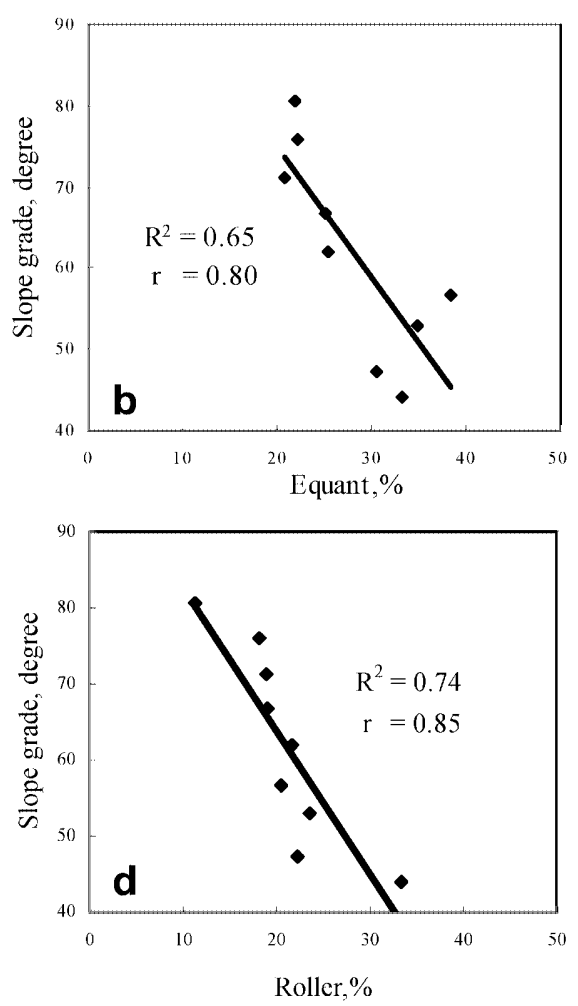

Fig. 9

Diagram exhibiting uniform grain orientation and high grade category of cobble slope. This result shows a significant, positive relationship between the slope grade with the intersected angle of strike on the cobble orientation and the slope surface
Fig. 10

The average results of the relationship between the slope grade and the percentage of disk and roller shapes. The average results were obtained from the slope grade with a $5^{\circ}$ measurement interval surface. When the intersected angle is $0^{\circ}$, the cobble orientation and slope surface forms a dip slope and the slope gradient ranges from 44 to $48^{\circ}$. When the intersected angle is $180^{\circ}$, an escarpment slope is formed and the slope gradient can reach 70 to $80^{\circ}$.

In practical terms, both the Linkou and Taoyuan terraces have statistically significant correlation coefficient $(r=0.74$, $0.77)$. The Tadu terrace has a lower correlation coefficient of $\mathrm{r}=0.44$ (Fig. 5 ).

The results from the three terraces show that the slope gradient changes according to the changes in the intersection angle of strike on the cobble orientation and slope surface. The slope gradient and the intersected angle of strike on the cobble orientation have a linear trend and a positive relationship. The combined figure (Fig. 5d) displays a significant correlation $(\mathrm{r}=0.61)$. This also reveals that the cobble orientation affects the anisotropy characteristics and the slope gradient.

\section{Grain shape relationship}

The distribution of disk, equant, bladed, and roller grain shapes in the three terraces were measured for comparison with the slope gradient. The results from the three terraces display a significant positive correlation $(\mathrm{r}=0.53,0.41$, and 0.55 ). The figures in the three terraces show a linear trend and a positive relationship (Fig. 6). An increase in the percentage of disk-shaped particles increases the slope gradient results. 
The three terraces display a negative correlation between the slope gradient and both equant and roller shapes (Figs. 7 and 8), whereas the slope gradient for bladeshaped particles display positive linear trends. This means that as the percentage of bladed particles increase, the slope gradient will also increase.

As the percentage of bladed and disk-shaped cobbles increase, the slope gradient will increase in the Linkou, Taoyuan, and Tadu terraces. In contrast, as the percentage of roller and equant cobbles increase, the slope gradient will decrease in these terraces.

\section{Matrix strength}

Both Matheson and Parent (1989) and Day (1993) point out that when the total cobble content in a terrace is lower than $70 \%$, the shear strength will be transferred from the cobble support to matrix support. To understand the relationship between the cobble orientation and its shapes, some of the slopes in the study areas were selected for study.

The intersection angle of the strike on the cobble orientation appears to influence the slope gradient when the unconfined compressive strength of the matrix is less than $42.5 \mathrm{kPa}$ (Table 5). The results show that the intersected angle of the strike on the cobble orientation ranges from 5 to $174^{\circ}$ and the slope gradient ranges from 44 to $80^{\circ}$ at the same unconfined compressive strength. They have a relatively high correlation coefficient of $r=0.79$. This means that the cobble orientation can influence the anisotropy characteristics of the geomaterial even when the unconfined compressive strength of the compared matrices is held constant.

\section{Discussion}

The rose diagrams show that if the grain orientation is uniform, a relatively high positive correlation $(\mathrm{r}=0.98)$ exists between grain orientation uniformity and slope gradient (Fig. 9).

These results also demonstrate that the cobble orientation has a higher anisotropy as the slope gradient changes. In contrast, the low-grade grain orientation (L) distribution in the rose diagram has no correlation with slope gradient. Therefore, when the grain orientation is random and rarely uniform, the cobble has more isotropy.

This study sought to minimize or avoid misjudgment in the diagram analysis from the data collected. Therefore, a change was made in the method of data collected. Individual data points within a $5^{\circ}$ range on the slope gradient were averaged together and given as one measures for the $5^{\circ}$ interval on the slope. Table 5 also shows that the slope gradient ranged from 40 to $84^{\circ}$ and divided into nine categories. The results revealed not only a clearly linear relationship in positive and negative directions but also a very significant correlation $(\mathrm{r}=0.95$ and 0.86$)$ in disk and roller shapes (Fig. 10). This method could reduce the error impact on the data collection and analysis.

\section{Conclusions}

The physical properties of matrices in lateritic cobbles are not different among the three terraces in the Linkou, Taoyuan, and Tadu areas. The cobble orientation will form anisotropy geomaterial and affect the distribution of the slope gradient.

The field results demonstrate that the difference in content percentage of various cobble shapes will affect slope gradient. The correlation of various data in the accompanying diagrams shows that the cobble shape and its orientation still affect slope gradient even when the matrix strength is constant. This means that even when cobble content is under $70 \%$ in the matrix support of lateritic cobbles, different cobble shapes and their orientation can still affect the stability of the cobble slope.

Acknowledgments The authors would like to express their thanks to the reviewer of the Editorial Board and Dr. Del Dobyns, Ming Chuan University, for their constructive comments, and to Ms. C.M. Yu for help in correcting the manuscript. Thanks are also extended to the National Science Council for their kind funding support.

\section{References}

Chen H, Chen RH (1991) Some engineering characteristics of Quaternary geology in Northern Taiwan. Acta Geol Taiwan 29:179-191

Chen RH (1990) The general study of landslide remedial method in lateritic terrace (in Chinese). Geohazard Report 78-73, National Science Council, Republic of China

Chen WF, Teng LS (1990) Depositional environment of Quaternary deposits of the Linkou tableland, northwestern Taiwan. Proc Geol Soc China 33(1):39-63

Chiang CR (1984) The report of an engineering geology investigation in the Taiwan community (in Chinese). Bull Cent Geol Surv 3(2):57-71

Day RW (1993) The engineering behaviour of a natural deposit of cobbles. Bull Int Assoc Eng Geol 30(2):213-254

Ho CS (1986) An introduction to the geology of Taiwan: explanatory text for the geologic map of Taiwan. Ministry of Economic Affairs, Republic of China, pp 15-48

Hung JJ, Kou JT, Chen RH (1985) The study of landslide and flood hazard in Linkou Terrace and its surrounding area (in Chinese). Geohazard Report 73-56, National Science Council, Republic of China, pp 3-10

Liao TN, Wu JS, Chang TL (1987) The preliminary investigation of potential hazard in Linkou area (in Chinese). Geohazard Report 75-40, National Science Council, Republic of China, pp 2-7

Lin SF (1991) The primary study of lateritic soil in Taoyuan Terrace (in Chinese). MSc Thesis, National Taiwan University Matheson GM (1986) Relationship between compacted rockfill density and gradation. J Geol Eng Am Soc Civil Eng 112(12):1119-1124

Matheson GM, Parent WF (1989) Construction and performance of two large rockfill embankments. J Geol Eng Am Soc Civil Eng 115(12):1699-1716

Nemec W, Steel RF (1984) Alluvial and coastal conglomerates: their significant features and some comments on gravelly massflow deposits. In: Koster EH, Steel RJ (eds) Sedimentology of 
gravels and conglomerates. Canadian Society of Petroleum Geologists Memoir 10, pp 1-31

Newill D (1962) A laboratory investigation of two red clays from Kenya. Géotechnique 11(4):302-318

Pettijohn FJ (1975) Sedimentary rocks, 3rd ed. Harper \& Row, New York

Tang CH (1964) Photogeologic interpretation of the Miaolu area, Taiwan, with special reference to its geologic structure. Proc Geol Soc China 2:11-19

Wagner AA (1957) The use of the Unified Soil Classification System by the Bureau of Reclamation. Proc 4th Int Conf Soil Mech Found Eng I, 125-126
Wan SM, Chen SH, Riu CT (1986) The relationship between the mineralogy, chemical characteristics and formation of lateritic soil in the weathered cobbles of Linkou Terrace (in Chinese). Geohazard Report 74-52B, National Science Council, Republic of China, pp 5-13

Yang KS (1986) Topographical study of active fault in Taiwan the relationship between the active fault and topography (in Chinese). PhD Thesis, Chinese Culture University

Zingg T (1935) Beitrage-zur Schotter analyses. Mineral Petrol Mitt Schweiz 15:39-140 